\title{
Maternal Mortality in an Iraqi Tertiary Hospital: Lessons From the Years of the Crisis
}

\author{
Reshed Zeki Obeid $^{1 * \mathbb{(}}$, Dina Akeel Salman², Zainab Abdul Ameer Jaafar ${ }^{2}$
}

\begin{abstract}
Objectives: Maternal mortality is a crucial indicator of health care provision within a nation, particularly during the periods of instability. This study aimed to assess the maternal mortality ratio in one of the largest hospitals in Baghdad over eight years including the time of the threat of the so-called Islamic State of Syria and Iraq.

Materials and Methods: A cross-sectional study was undertaken by reviewing the records of mothers who passed away in the hospital from February 2011 to February 2018. The gathered data included the patients' demographic features as well as obstetrical and medical conditions and causes of death each year.

Results: During the eight years, the total live births numbered 95800 while 52 mothers died for a maternal mortality ratio of 58.12 per $10^{5}$. Most of the deceased mothers aged between 30 and 39 years $(P=0.0015)$, were multiparous and from rural residence $(P=$ $0.000)$, booked no antenatal care $(P=0.0014)$, and completed delivery via a cesarean section $(P=0.0184)$. The majority died in the postpartum period $(P=0.000)$ within the first 12 hours of admission $(P=0.000)$. Finally, the major presentation and cause of death were often obstetrical hemorrhage.

Conclusions: The maternal mortality was high and obstetrical hemorrhage was the main cause of death. In addition, the majority of patients died within the first 12 hours of admission, which is attributed to delays in access to the hospital and the lack of needed facilities during that critical period of time.

Keywords: Iraq, Maternal mortality, Obstetrical hemorrhage
\end{abstract}

\section{Introduction}

Maternal death is considered as a great tragedy at family and society levels. Every minute, a mother dies due to pregnancy and childbirth around the world and the vast majority of cases occur in developing countries (1). The measles, mumps, and rubella (MMR) vaccine can thus be considered as a measure of health care provision in a given country (2).

The World Health Organization (WHO) defines maternal death as the "loss of the life of a female while she is pregnant or during 42 days after the cessation of pregnancy, irrespective of the length of pregnancy, from any reason associated with or worsened by the pregnancy or its management, but not from accidental or incidental causes" (2). The maternal death ratio is the entirety of maternal deaths during a given period per 100,000 live births during a similar interval period $(3,4)$.

An evaluation of the risk factors of maternal death is crucial for creating a comprehensive approach regarding eliminating pregnancy-related challenges. To this end, a solid, comprehensive, and prospective plan is required, involving both therapeutic and social elements specific to maternal mortality. Such a plan would be based on patient records that can longitudinally track maternal death rates (5). Iraq has suffered unique and exceptional circumstances as a nation prior to and during the study period such that the causes and the risk factors (or the MMR) might differ from those of nearby countries. The rationale behind the current study was to uncover the MMR in the largest tertiary hospital in Baghdad as the capital of Iraq. This study was conducted during a critical period in the country, the time of the so-called threat of the Islamic State of Iraq and Syria, and the armed conflict in wide areas to the west and north of Baghdad. The study attempted to uncover whether the causes of maternal mortality in this geographic area were related to this crisis, specifically to the displacement of hundreds of thousands of people, the existence of areas lacking even minimal health care facilities and the great available challenges in accessing the nearest facilities.

\section{Patients and Methods}

Study Design

The present cross-sectional study was conducted through a review of records in the Department of Obstetrics and Gynecology of the Al-Yarmouk Teaching Hospital in Baghdad, Iraq. This hospital is considered to be one of the community's tertiary doctors' facilities, receiving

Received 7 January 2020, Accepted 19 April 2020, Available online 18 October 2020

${ }^{1}$ Department of Obstetrics and Gynecology, College of Medicine, Al-Anbar University, Iraq. ${ }^{2}$ Department of Obstetrics and Gynecology, College of Medicine, Al-Mustansiriyah University, Iraq.

*Corresponding Author: Reshed Zeki Obeid, Tel: +9647705340920, Email: reshedzeki@uoanbar.edu.iq 


\section{Key Messages}

- Maternal mortality is an important aspect of women's health care in all parts of the world.

- Exceptional situations such as wars and displacement will negatively affect the health system of the country particularly maternal wellbeing.

obstetrical and gynecological crisis cases 24 hours daily. In addition, it is one of the principal referral clinics in the region, catering to a huge population of pregnant women in Baghdad.

\section{Data Collection}

As the subject of the study was maternal mortality, the selection criteria included all pregnant ladies who were admitted to the hospital. Once mortality occurred, the information of the patient was obtained from the patient's file, the mortality conference of the hospital, and postmortem reports.

Ultimately, the hospital records of women, who died of pregnancy-related difficulties at the Al-Yarmouk Teaching Hospital from February 2011 to February 2018, were included in this study. The study involved 52 women aged between 15 and 45 years.

The collected data included patients' ages, obstetrical data, presentation, parity, any previous medical disease, mode of delivery, place of delivery, gestational age of the fetus at the time of the mother's death, the type(s) of medical interventions in the hospital, and the cause of death. Further, the primary cause of death was obtained from the postmortem report generated through forensic medicine, and the maternal mortality rate was calculated per 100000 live births (6). The data were obtained from Hospital Management Information Systems. The included women were insured of data confidentiality.

\section{Statistical Analysis}

All data were coded and a double-check was performed on any missing data. The Statistical Package for the Social Sciences, version 25 (IBM Corp., Armonk, NY, USA) was used for data analysis, categorical data were represented by frequencies and percentages. The association between variables was measured using a $t$ test (i.e., one-sample $t$ test between the percentages to determine whether there was a significant difference). An alpha level of $<0.05$ was considered to be statistically significant and p-values were used to test the associations between different demographics.

\section{Results}

A total of 95800 live births occurred at the Al-Yarmouk Teaching Hospital from January 2011 through December 2018. During these deliveries, 52 mothers died, thus the maternal death rate was in the range of $17-79$ per $10^{5}$.
Furthermore, the maternal mortality rate per $10^{5}$ was lowest in 2016 while the highest rate was related to 2018 with an MMR of 58.12 per $10^{5}$ during the total study period (Figure 1).

Most women in the study aged between 30 and 39 years $(P=0.0015)$, were of rural residence $(P=0.000)$, and had limited education $(P=0.0206)$ while they did not book for antenatal care $(P=0.0014)$, the details of which are provided in Table 1.

The majority of demised mothers presented in the postpartum period $(P=0.000)$ died within the first 12 hours of hospital admission $(P=0.000)$. As the main mode of delivery was by cesarean section (CS, $P=0.000$ ), some required various surgical interventions, and more than half of the women needed respiratory care unit admission (Table 2).

Nearly half of the deceased mothers had previously been healthy. However, a quarter of this population was anemic and a few were hypertensive (Figure 2).

Moreover, most women either experienced postpartum hemorrhage $(30.8 \%)$ or antepartum hemorrhage (17.3\%) or presented during parturition (13.5\%). For these reasons, the predominant cause of death $(36.5 \%)$ was obstetrical hemorrhage (Figures 3 and 4).

\section{Discussion}

Maternal mortality is a devastating end-result of various obstetrical and medical risk factors. It can also be related to social factors and local crises.

During the study period, the MMR in the Al-Yarmouk Hospital ranged from 17 per $10^{5}$ in 2016 to 79 per $10^{5}$ in 2018. (It should be noted that the reduction in the MMR during 2016 partly occurred since admissions were restricted following an accidental fire that affected the hospital). The MMR during this eight-year period was 58.12 per $10^{5}$. This is in line with the results published by the Global Burden of Disease Study 2015 Maternal Mortality Collaborators (7), which was a systemic analysis at the global, regional, and national levels of maternal mortality over 15 years, and the results revealed that the MMR in Iraq was as high as 58.6 per $10^{5}$. The MMR in

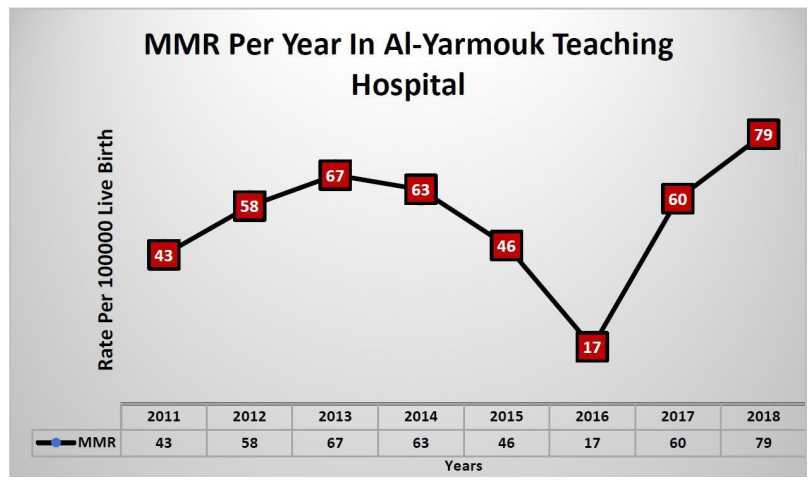

Figure 1. The Maternal Mortality Rate in the Al-Yarmouk Teaching Hospital per Year (2011-2018). Note. MMR: maternal mortality rate. 


\begin{tabular}{llll}
\multicolumn{3}{l}{ Table 1. Demographic Features of Patients } \\
\hline Variables & & Total, $\mathbf{n}(\%)$ & $\boldsymbol{P}$ Value \\
\hline \multirow{4}{*}{ Age groups (y) } & $20-29$ & $6(11.5)$ & \\
& $30-39$ & $7(13.5)$ & $0.0015^{*}$ \\
& $\geq 40$ & $29(55.8)$ & \\
& 0 & $10(19.2)$ & \\
Parity & $1-4$ & $17(32.7)$ & \\
& $>4$ & $12(23.1)$ & 0.34 \\
Residence & Urban & $23(44.2)$ & \\
& Rural & $12(23.1)$ & $0.000^{*}$ \\
& Illiterate & $40(76.9)$ & \\
Education & Primary school & $12(23.1)$ & \\
& Secondary school & $9(17.3)$ & $0.0206^{*}$ \\
& Postsecondary school & $5(9.6)$ & \\
ANC & Booked & $15(28.8)$ & $0.0014^{*}$ \\
& Not booked & $37(71.2)$ & \\
\hline
\end{tabular}

Note. ANC: Antenatal care; ${ }^{*} P \leq 0.05$ is considered statistically significant.

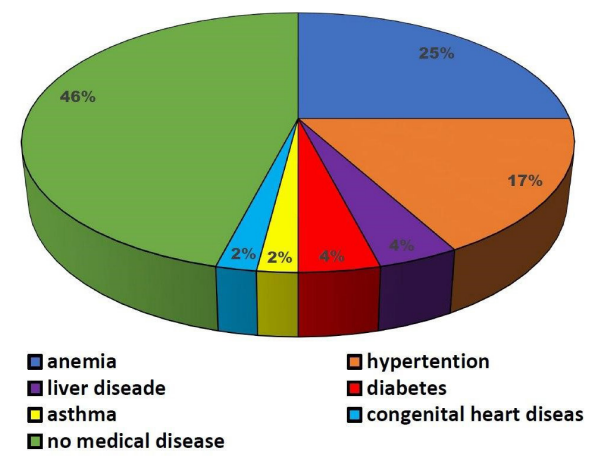

Figure 2. History of Known Disease Among the Study Group Participants

Iraq is higher compared to most of the neighboring countries. By comparison according to (7), Syria (54.1 per $10^{5}$ ) suffers similar critical circumstances $(8,9)$ while other nearby rates include Jordan (24.2 per $\left.10^{5}\right)$, Iran (20.8 per $\left.10^{5}\right)$, Turkey $\left(15.8\right.$ per $\left.10^{5}\right)$, Saudi Arabia (15.7 per $\left.10^{5}\right)$, and Kuwait $\left(5.9\right.$ per $\left.10^{5}\right)$.

The highest age group among the deceased mothers was 30-39 years old, which corroborates with the results of the study by Nove et al (10). This fact is likely related to the higher parity in this age group. Similarly, those having more than four deliveries were dominant in the study group, which is in conformity with the study by Ntoimo et al (11). The majority of the deceased mothers had a poor education level and rural residence, which agrees with the findings of Singh et al (12) and Al-Kayat (13). This, in turn, can lead to a lack of facilities and greater obstacles in accessing health care services. In addition, the lack of antenatal care was one of the main features of the study group, which is in line with the findings of Anastasi et al (14). The results of the present study also agree with those
Table 2. Obstetrical and Surgical Interventions on Behalf of the Patients

\begin{tabular}{|c|c|c|c|}
\hline \multicolumn{2}{|l|}{ Variables } & \multirow{2}{*}{$\frac{\text { No. (\%) }}{16(30.8)}$} & \multirow{2}{*}{$\frac{P \text {-value }}{0.204}$} \\
\hline Gestational age (wk) & $<34$ & & \\
\hline & $34-37$ & $24(46.2)$ & \\
\hline & $>37$ & $12(23.1)$ & \\
\hline \multirow{3}{*}{$\begin{array}{l}\text { Time interval from } \\
\text { admission to death } \\
\text { (hours) }\end{array}$} & $0-12$ & $37(71.2)$ & $0.000^{*}$ \\
\hline & $12-24$ & $5(9.6)$ & \\
\hline & $>24$ & $10(19.2)$ & \\
\hline \multirow[t]{3}{*}{ Time of presentation } & Antepartum & $6(11.5)$ & $0.000^{*}$ \\
\hline & Postpartum & $44(84.6)$ & \\
\hline & Postabortion & $2(3.8)$ & \\
\hline \multirow{2}{*}{$\begin{array}{l}\text { Type of delivery in the } \\
\text { current pregnancy }\end{array}$} & Vaginal delivery & $17(34)$ & $0.0184^{*}$ \\
\hline & Caesarian section & $33(66)$ & \\
\hline \multirow[t]{2}{*}{ Needed RCU } & Yes & $29(55.8)$ & 0.403 \\
\hline & No & $23(44.2)$ & \\
\hline \multirow{2}{*}{$\begin{array}{l}\text { Surgical interventions } \\
\text { in the hospital }\end{array}$} & Yes & $20(38.5)$ & 0.094 \\
\hline & No & $32(61.5)$ & \\
\hline \multirow[t]{5}{*}{ Type of intervention } & Cesarean section & $4(20)$ & 0.000 \\
\hline & $\begin{array}{l}\text { Cesarean } \\
\text { hysterectomy }\end{array}$ & $5(25)$ & \\
\hline & Subtotal hysterectomy & $6(30)$ & \\
\hline & $\begin{array}{l}\text { Subtotal hysterectomy } \\
+ \text { internal iliac artery }\end{array}$ & $4(20)$ & \\
\hline & $\begin{array}{l}\text { Second-look } \\
\text { laparotomy for } \\
\text { internal bleeding }\end{array}$ & $1(5)$ & \\
\hline
\end{tabular}

Note. RCU: resuscitative care unit; ${ }^{*} P \leq 0.05$ is considered statistically significant.

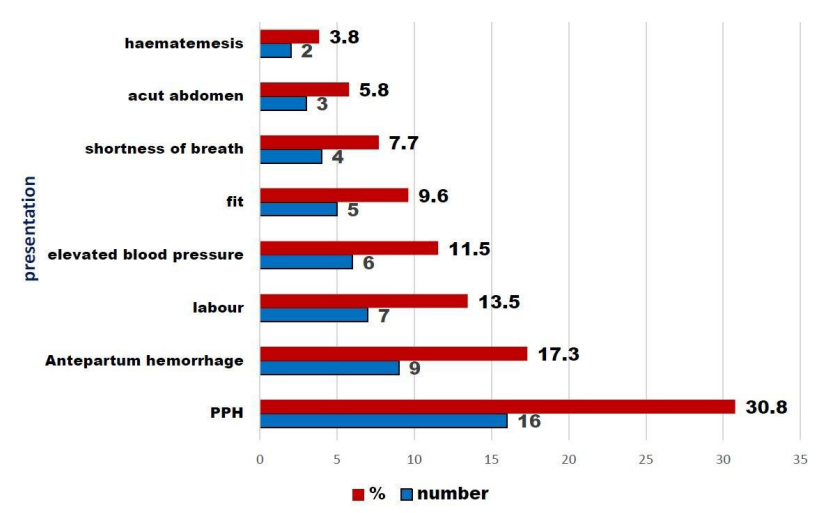

Figure 3. Presentation at the Time of Admission.

of Berhan et al (15), demonstrating an inverse correlation between the number of antenatal care visits and maternal mortality. Interestingly, Adjiwanou et al (16) noted that the educational levels of both parents constitute an important determinant of whether they will seek antenatal care and the assistance of skilled personnel during the actual labor and delivery.

Given that most cases were referrals from elsewhere and the study period coincided with the time of crisis in the 


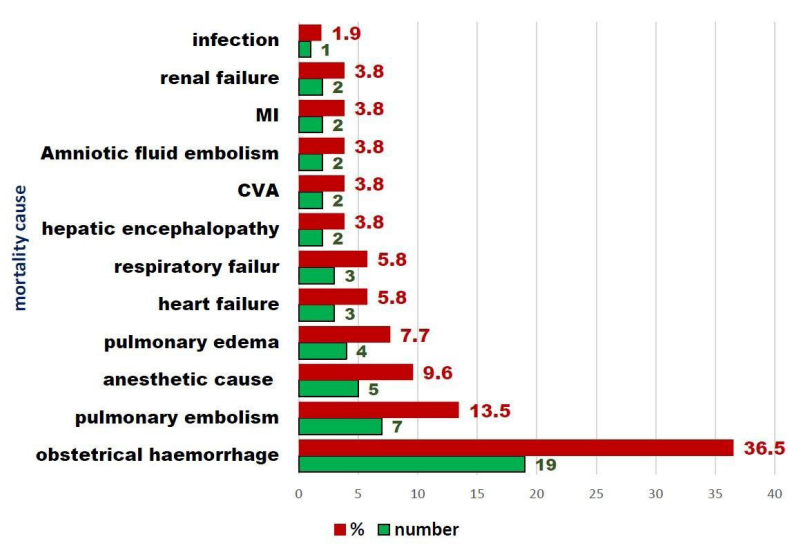

Figure 4. Causes of Death Among the Members of the Study Group.

country, most women in the study died within the first 12 hours of arrival at the hospital largely due to the lack of facilities and delays in the transportation of critical cases. In addition, the vast majority of the dead mothers were in their postpartum period, which is in conformity with the study of Al-Kayat (13). The fact that the puerperium is the period when women are most susceptible to complications, making it no surprise that this period was characterized by most recorded maternal deaths (17).

In the current study, most of the dead women delivered their babies by a CS. This event corresponds to the results of Bauserman et al (5) and Kallianidis et al (18). In their study, Kallianidis et al (18) concluded that the maternal mortality rate was three times higher following CS delivery as compared with vaginal delivery, provided that deaths related to surgery were excluded from the investigation. This is not surprising insofar as CS by itself has a high morbidity rate, and therefore, a higher risk of mortality.

However, Molina et al (19) reported contrary results in their study on 194 countries for the WHO. Based on their results, no linear correlation was found between delivery by CS and maternal or neonatal mortality, indicating that the rates of CS at 19 per 100 live births would be associated with a lower maternal or neonatal mortality among WHO member states at the national level (19).

Although women who died in this study had no known medical illness at the time of presentation, a quarter of patients were anemic. In a systematic analysis of population-representative data made by Stevens et al (20), anemia was found to be prevalent in $37 \%$ of pregnant women in central Asia, the Middle East, and North Africa, including the Iraqi population. More precisely, severe anemia is a leading cause of obstetric hemorrhage, shock, and heart failure, which are, in turn, considered as the leading causes of maternal mortality, which was noted by Singh et al (12).

Obstetric hemorrhage was the main presentation and cause of death in the current study, which agrees with the findings of Kassebaum et al (7), Agampodi et al (6), and Singh et al (12). Similarly, Mokdad et al (21) focused on maternal mortality in the eastern Mediterranean countries and stated that obstetric hemorrhage was the leading cause of maternal mortality in Iraq with a rate of 3.04 per 100000 live births, followed by hypertensive disorders with a mortality rate of 1.04 per 100000 live births. This preventable and treatable condition remains the leading cause of maternal mortality worldwide, which is implicated in more than half of all maternal deaths in some parts of the globe $(22,23)$. In $2017,30 \%$ of maternal mortality cases in Iraq occurred due to obstetric hemorrhage (24), which is a considerably lower rate than that of the current study. It is important to bear in mind the length of the period of this study, along with the fact that the study period included the years of armed conflicts, displacement, and the lack of facilities in the cities to the west and north of Baghdad. Thaddeus and Maine (21) indicated that three specific types of delay, including a delay in seeking care, a delay in reaching the health care facility, and a delay in receiving health care in the facility once it is reached, might have impacted pregnant women, potentially leading to the suboptimal management of obstetrical hemorrhage and thus higher maternal mortality. Other than those mothers who arrived at the hospital in a fit condition, the other mainly noted presentation was hypertension. This accounts for the fact that many of the causes of death (e.g., pulmonary edema, heart failure, cerebrovascular accident, and respiratory failure) are among the complications of hypertensive disorders. Approximately 50000 maternal deaths occur every year as a result of eclampsia worldwide, which accounts for the majority of deaths in low-income countries (25). Eclampsia was found to be the major cause of death among women in the studies of Ntoimo et al (11) and Das and Biswas (26).

On the other hand, Jabir et al (27) undertook a multicenter study on maternal near-miss cases in Baghdad and found that both obstetrical hemorrhage and hypertension were the most common causes of severe maternal morbidity and life-threatening situations.

The present study had some limitations. The main limitation was that it only included cases from one tertiary hospital as it was difficult to obtain data from the nearby hospitals. Other limitations were the lack of using electronic death registration and concerns about the accuracy of reports detailing the cause of maternal death.

In conclusion, at a tertiary hospital in Baghdad, obstetrical hemorrhage was responsible for more than one-third of maternal deaths, and most of these women died within 12 hours of arrival at the hospital. These facts indicate the tragic effect of delay in reaching the hospital, as well as the consequences of the lack of facilities, difficulties that were all highly common in health care at the critical time period covered in this study.

Considering that obstetrical hemorrhage is the main cause of death, it is suggested that a multicenter study be conducted on maternal demise among obstetrical hemorrhage cases, paying special attention to how to 
reduce this preventable devastating end-result.

\section{Authors' Contribution}

RZO did writing and editing of the manuscript. DAS designed and did data collection. ZAAJ designed, did data collection and statistical analysis.

\section{Conflict of Interests}

Authors declare that they have no conflict of interests.

\section{Ethical Issues}

The protocol of this study was approved by the local Ethical Research Committee on Obstetrics and Gynecology. Informed written consent was obtained from relatives of all deceased women who were included in the study.

\section{Financial Support}

The research was funded by the authors.

\section{References}

1. Dutta DC. Safe motherhood, Epidemiology in obstetrics. In: Konar H, ed. DC Dutta's Textbook in Obstetrics. 8th ed. New Delhi, India: Jaypee Brothers Medical Publishes; 2016:683.

2. MacDorman MF, Declercq E, Cabral H, Morton C. Recent increases in the U.S. maternal mortality rate: disentangling trends from measurement issues. Obstet Gynecol. 2016;128(3):447-455. doi:10.1097/aog.0000000000001556

3. Overview of obstetrics. In: Gary Cunningham F, Leveno KJ, Bloom SL, et al, eds. William's Obstetrics. 25th ed. McGrawHill Education; 2018:29.

4. Pasupathy D. Perinatal epidemiology and statistics. In: Edmonds K, Lees C, Bourne T, eds. Dewhurst's Textbook of Obstetrics \& Gynaecology. Hoboken, NJ: Wiley-Blackwell; 2018:416.

5. Bauserman M, Lokangaka A, Thorsten V, et al. Risk factors for maternal death and trends in maternal mortality in lowand middle-income countries: a prospective longitudinal cohort analysis. Reprod Health. 2015;12(Suppl 2):S5. doi:10.1186/1742-4755-12-s2-s5

6. Agampodi S, Wickramage K, Agampodi T, et al. Maternal mortality revisited: the application of the new ICD-MM classification system in reference to maternal deaths in Sri Lanka. Reprod Health. 2014;11(1):17. doi:10.1186/17424755-11-17

7. GBD 2015 Maternal Mortality Collaborators. Global, regional, and national levels of maternal mortality, 19902015: a systematic analysis for the Global Burden of Disease Study 2015. Lancet. 2016;388(10053):1775-1812. doi:10.1016/s0140-6736(16)31470-2

8. Cousins S. Syrian crisis: health experts say more can be done. Lancet. 2015;385(9972):931-934. doi:10.1016/s01406736(15)60515-3

9. Ben Taleb Z, Bahelah R, Fouad FM, Coutts A, Wilcox M, Maziak W. Syria: health in a country undergoing tragic transition. Int J Public Health. 2015;60 Suppl 1:S63-72. doi:10.1007/s00038-014-0586-2

10. Nove A, Matthews Z, Neal S, Camacho AV. Maternal mortality in adolescents compared with women of other ages: evidence from 144 countries. Lancet Glob Health. 2014;2(3):e155-164. doi:10.1016/s2214-109x(13)70179-7

11. Ntoimo LF, Okonofua FE, Ogu RN, et al. Prevalence and risk factors for maternal mortality in referral hospitals in Nigeria: a multicenter study. Int J Womens Health. 2018;10:69-76. doi:10.2147/ijwh.s151784

12. Singh K, Puri S, Chopra G. Maternal mortality in India: an overview of social causes. Int J Sci Res Publ. 2018;8(3):7-14. doi:10.29322/ijsrp.8.3.2018.p7503

13. Al-Kayat ES. Maternal mortality in cities of Iraq for three years. Int J Curr Microbiol Appl Sci. 2016;5(1):590-611. doi:10.20546/ijcmas.2016.501.061

14. Anastasi E, Borchert M, Campbell OM, et al. Losing women along the path to safe motherhood: why is there such a gap between women's use of antenatal care and skilled birth attendance? a mixed methods study in northern Uganda. BMC Pregnancy Childbirth. 2015;15:287. doi:10.1186/ s12884-015-0695-9

15. Berhan $Y$, Berhan A. Antenatal care as a means of increasing birth in the health facility and reducing maternal mortality: a systematic review. Ethiop J Health Sci. 2014;24:93-104. doi:10.4314/ejhs.v24i0.9s

16. Adjiwanou V, Bougma M, LeGrand T. The effect of partners' education on women's reproductive and maternal health in developing countries. Soc Sci Med. 2018;197:104115. doi:10.1016/j.socscimed.2017.11.054

17. Weeks AD. The peurperium. In: Kenny LC, Myers JE, eds. Obstetrics by Ten Teachers. Boca Raton: CRC Press; 2017:520.

18. Kallianidis AF, Schutte JM, van Roosmalen J, van den Akker T. Maternal mortality after cesarean section in the Netherlands. Eur J Obstet Gynecol Reprod Biol. 2018;229:148-152. doi:10.1016/j.ejogrb.2018.08.586

19. Molina G, Weiser TG, Lipsitz SR, et al. Relationship between cesarean delivery rate and maternal and neonatal mortality. JAMA. 2015;314(21):2263-2270. doi:10.1001/ jama.2015.15553

20. Stevens GA, Finucane MM, De-Regil LM, et al. Global, regional, and national trends in haemoglobin concentration and prevalence of total and severe anaemia in children and pregnant and non-pregnant women for 1995-2011: a systematic analysis of population-representative data. Lancet Glob Health. 2013;1(1):e16-25. doi:10.1016/s2214$109 x(13) 70001-9$

21. GBD 2015 Eastern Mediterranean Region Maternal Mortality Collaborators. Maternal mortality and morbidity burden in the Eastern Mediterranean Region: findings from the Global Burden of Disease 2015 study. Int J Public Health. 2018 May;63(Suppl 1):47-61. doi:10.1007/s00038017-1004-3

22. McCarthy F. Obstetric emergencies. In: Kenny LC, Myers JE, eds. Obstetrics by Ten Teachers. Boca Raton: CRC Press; 2017:492.

23. Knight M, Tuffnell D, Kenyon S, Shakespeare J, Gray R, Kurinczuk JJ. Saving Lives, Improving Mothers' Care: Surveillance of Maternal Deaths in the UK2011-13 and Lessons Learned to Inform Maternity Care from the UK and Ireland Confidential Enquiries into Maternal Deaths and Morbidity 2009-13. Oxford: National Perinatal Epidemiology Unit, University of Oxford; 2015.

24. Annual Statistical Report 2016. Baghdad: Iraqi Ministry of 
Health and Environment. 2017.

25. Abalos E, Cuesta C, Carroli G, et al. Pre-eclampsia, eclampsia and adverse maternal and perinatal outcomes: a secondary analysis of the World Health Organization Multicountry Survey on Maternal and Newborn Health. Bjog. 2014;121 Suppl 1:14-24. doi:10.1111/1471-0528.12629

26. Das R, Biswas S. Eclapmsia: the major cause of maternal mortality in Eastern India. Ethiop J Health Sci. 2015;25(2):111-116. doi:10.4314/ejhs.v25i2.2

27. Jabir M, Abdul-Salam I, Suheil DM, et al. Maternal near miss and quality of maternal health care in Baghdad, Iraq. BMC Pregnancy Childbirth. 2013;13:11. doi:10.1186/14712393-13-11

C 2020 The Author(s); This is an open-access article distributed under the terms of the Creative Commons Attribution License (http:// creativecommons.org/licenses/by/4.0), which permits unrestricted use, distribution, and reproduction in any medium, provided the original work is properly cited. 